\title{
Evaluation of performance metrics of leagile supply chain through fuzzy MCDM
}

\author{
D. Venkata Ramana ${ }^{a}$, K.Narayana Rao ${ }^{b *}$ and J. Suresh Kumar ${ }^{a}$
}

${ }^{a}$ Department of Mechanical Engg, J.N.T.University, Hyderabad- 500083, India

${ }^{b}$ Department of Mechanical Engg, Govt. Polytechnic, Visakhapatnam- 530007, India

\section{H R O N I C L E}

Article history:

Received October 2, 2012

Received in Revised Format

March 12, 2013

Accepted March 14, 2013

Available online

March 152013

Keywords:

Leagile supply chain

Confirmatory factor analysis

Triangle fuzzy weights

\section{A B S T R A C T}

\begin{abstract}
Leagile supply chain management has emerged as a proactive approach for improving business value of companies. The companies that face volatile and unpredictable market demand of their products must pioneer in leagile supply chain strategy for competition and various demands of customers. There are literally many approaches for performance metrics of supply chain in general, yet little investigation has identified the reliability and validity of such approaches particularly in leagile supply chains. This study examines the consistency approaches by confirmatory factor analysis that determines the adoption of performance dimensions. The prioritization of performance enablers under these dimensions of leagile supply chain in small and medium enterprises are determined through fuzzy logarithmic least square method (LLSM). The study developed a generic hierarchy model for decision-makers who can prioritize the supply chain metrics under performance dimensions of leagile supply chain.
\end{abstract}

(C) 2013 Growing Science Ltd. All rights reserved.

\section{Introduction}

Supply Chain Management has been defined by "The Council Of Logistics Management" (2000) as "the systematic, strategic coordination of the traditional business functions and tactics across these businesses functions within a particular organization and across businesses within the supply chain, for the purpose of improving the long term performance of the individual organizations and the supply chain as a whole" (Li et al., 2005). Supply chain can be considered as a set of activities that are used by any firm to provide value for its customer either as a product or service, or a combination of both (Samaranayake, 2005). Leagile supply chain is defined as the combination of lean and agile paradigms that, applied to the strategy of supply chain, respond satisfactorily, to the volatile market demands (Van Hoek et al., 2001). There is an important difference between the performance of lean supply chain and agile supply chain. Generally, lean supply chains (or efficient) are appropriate for functional stable products and services, while the agile supply chain (or responsive) are better suited for products and services that are innovative and less predictable (Slack et al., 2008). Leagile supply

\footnotetext{
* Corresponding author

E-mail addresses: nr_kandukuri@rediffmail.com(K. Narayana Rao)

C 2013 Growing Science Ltd. All rights reserved.

doi: $10.5267 /$ j.dsl.2013.03.003
} 
chain has not been considered as a strategic concept, it can be thought of as a support for the cumulative model of lean and agile practices, because the leagility allude to some degree of the overlap between leanness and agility (Narasimhan, et al. 2006). To achieve leagility the de-coupling point is be located at the final assembler. An action that usually requires is product rationalization (Hau \& Margurita, 1995). Specific products are now pulled by current sales demand whilst upstream of the de-coupling point suppliers now work to level schedules.

Hsu and $\mathrm{Hu}$ (2008) examined the consistency approaches by factor analysis, which determines the adoption and implementation of green supply chain management in Taiwanese electronic industry. The fuzzy analytic hierarchy process method is applied to prioritize the relative importance of four dimensions and twenty approaches among nine enterprises in electronic industry.

Motadel et al. (2011) identified and prioritized five supply chain agility indicators in the automotive industry of Tehran. The results proved that among the five dimensions of supply chain agility, Information Technology and Flexibility are the most important indicators. Agarwal et al. (2006) proposed a framework, which encapsulated the market sensitiveness, process integration information driver and flexibility measures of supply chain performance. The proposed framework analyzed the effect of market winning criteria and market qualifying criteria on the three types of supply chains: lean, agile and leagile.

Gunasekaran et al. (2004) developed a framework to promote a better understanding of the importance of SCM performance measurement and metrics. Arawati et al. (2008) analyzed the relationships between strategic supplier partnership practices, product quality performance and business performance and their associations through correlation, cluster analysis and Structural Equation Modeling (SEM).

Bhatnagar and Sohal (2005) identified the manufacturing industry of Asian as the research targets and proposed supply chain performance measurement indicators on plant location factor, supply chain uncertainty and manufacturing practices to measure supply chain competitive advantages. Özkir and Demirel (2011) explored some strategies for design and performance measurement of different supply chain types based on fuzzy entropy approach. Sower and Abshire (2011) examined the impact of RFID technology utilization on organizational agility in manufacturing firms. The results showed that the implementation of RFID technology could result in improved organizational agility resulting in improved performance.

From the current literature, it is observed that performance measurement and metrics pertaining to leagile supply chains have not received adequate attention from researchers or practitioners. Hence, in this paper, a generic hierarchical model for leagile supply chain performance measurement is developed through CFA. Further, weights of the enablers under each performance determinant are determined in fuzzy environment.

\section{Performance measures of leagile supply chain}

\subsection{Organizational Performance (ORP)}

The definition of organizational performance depends on the views of different stakeholders. According to Vickery et al. (2007), organizational performance refers to how well an organization achieves its market-oriented goals as well as its financial goals. Thus, they set up the measurement performance items as return on assets, market share and growth rate. This study followed the indicators adopted by Barua et al. (2004) and $\mathrm{Li}$ et al. (2006) as the base for designing the questionnaire evaluating organizational performance, including market share, sale growth, ROI and green image. The items of organizational performance (Chen et al., 2006) measurement was based on 
the related executives' evaluation and judgment with regard to the market share, sale growth and profit margin on sales of the company (comparing with the last year). The item scales are five-point Likert scales with $1=$ significant decrease, 2 = decrease, $3=$ same as before, $4=$ increase, $5=$ significant increase.

\subsection{Organizational Performance (OP)}

Lippman (2001) interviewed operations managers and reported that most of them claimed they were experiencing increases in their operational outcomes, such as reduction in cycle time, cost and quality improvement. In this study, product cycle time, due date performance, cost and quality are considered as performance enablers under operational performance. These enablers will influence the competitors of the market. Questions were based on Likert five-point scale for evaluating the managers' perception on each performance enabler.

\subsection{Customer Service Performance (CSP)}

Customer service performance is the ability to respond to customers' ever-changing wants and needs in a timely way (Zelbst et al., 2010). The utilization of technologies such as RFID can lead to agility in organizations. Agile organizations have the capability to respond to unexpected changes and increase processing speed, thus increasing customer service performance. The integration of information technology is likely to result in more agility for an organization resulting in better response to market changes as well as enhancing the capability to sense, perceiving and anticipating market changes. In this study, customer satisfaction, delivery dependability, responsiveness and order fill capacity are considered as performance enablers under logistic performance. . Questions were based on Likert five-point scale for evaluating the managers' perception on each performance enabler.

\subsection{Flexibility (FL)}

According to Slack (1987), flexibility is defined as two dimensional, Swafford et al, (2006) defined flexibility using two dimensions called range and adaptability. Range is defined as the number of different positions, or flexible options achieved with existing resources. Adaptability is the ability to change the existing number of states. In this study, product development flexibility, sourcing flexibility, manufacturing flexibility, and information technology flexibility are considered as performance enablers under flexibility. Questions were based on Likert five-point scale for evaluating the managers' perception on each performance enabler.

\section{The conceptual model}

The proposed model is based on four performance indicators- (i) Operational Performance (OP); (ii) Customer Service Performance (CSP), (iii) Organizational Performance (ORP) (iv) Flexibility (FL). In this study, in order to determine the domain that encompasses Leagile performance dimensions exhaustive theoretical, empirical and practitioner literature were reviewed. A conceptual frame work is developed by incorporating ideas, theories and studies from literature. The conceptual frame work is shown in the Fig. 1.

\subsection{Hypotheses}

Research Question: How the above performance enablers will influence the legality of a supply chain?

In this context, the following hypotheses are introduced.

$\mathrm{H}_{1}$ : Enablers of operational Performance (OP) constitute an indicator of leagile supply chain 
Performance

$\mathrm{H}_{2}$ : Enablers of Customer Service Performance (CSP) constitute an indicator of leagile

supply chain Performance

$\mathrm{H}_{3}$ : Enablers of organizational Performance (ORP) constitute an indicator of leagile supply chain performance

$\mathrm{H}_{4}$ : Enablers of flexibility (FL) constitute an indicator of leagile supply chain performance

This study examines the consistency approaches by confirmatory factor analysis that determines the construct validity, convergent validity and internal consistency of performance enablers of leagile supply chain. Further, the weights of the performance enablers under each performance indicator are determined by using Fuzzy Analytic Hierarchy Process (FAHP).

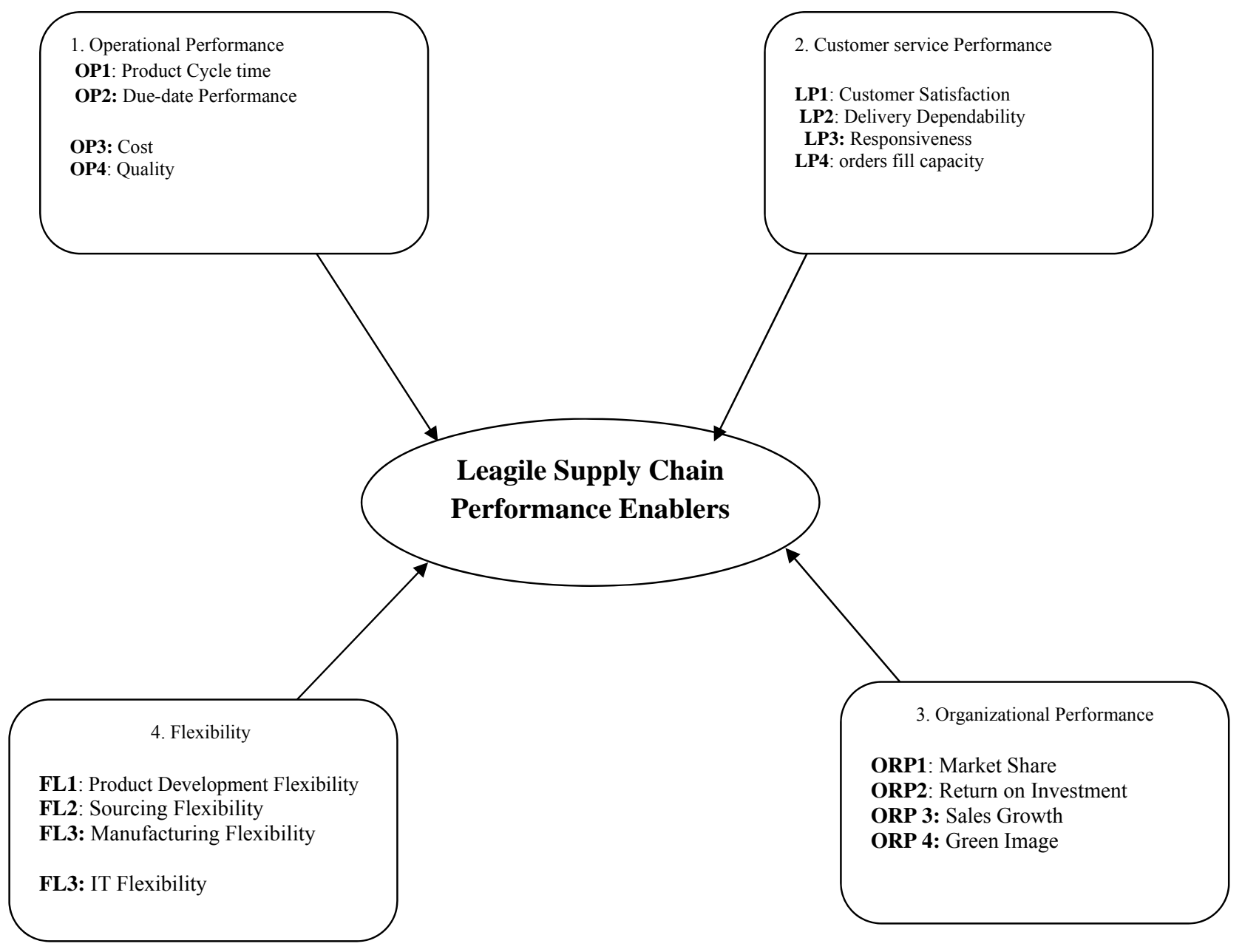

Fig. 1. The Conceptual Frame work of Leagile Supply Chain Performance Enablers

\subsection{Confirmatory Factor analysis}

CFA requires the specification of a factor model, including the number of factors and the pattern of zero and nonzero loadings on those factors. A small number of theory-driven competing models might be specified as well. CFA provides information on how well the hypothesized model explains the relations among the variables. CFA has the advantages of allowing hypothesis testing on the data. The confirmatory factor analysis was done using LISREL 8.5. The measurement model fit with the data was checked with chi-square goodness-of-fit, and approximate fit indexes. Insignificant model chi-square goodness-of-fit (set at 0.05) signifies model fit. For approximate fit indexes, Goodness of 
Fit Index (GFI), Adjusted Goodness of Fit Index (AGFI), Normed fit index (NFI), relative fit index (RFI), incremental fit index (IFI), Tucker-Lewis fit index (TFI) and comparative fit index (CFI) of above 0.9 would indicate model fit . For another approximate fit index, root mean square error of approximation (RMSEA), a value less than 0.08 Root Mean Squared Residual (RMR) value less than 0.05 would signify reasonable model fit. Significance of standardized regression weight (standardized loading factor) estimates signifies that the indicator variables are significant and representative of their latent variable.

\subsection{Fuzzy analytical hierarchy process (FAHP)}

In Analytic Hierarchy Process, vagueness in the decision maker's subjective judgments are not incorporated in determining the relative weights of the criteria. In order to eliminate this limitation, fuzzy modification of the AHP, is necessary for tackling the above uncertainty and imprecision of the process.

\subsubsection{Determination of priorities from fuzzy pair wise comparison matrix}

The assessment of local priorities, based on pair wise comparisons needs some prioritization method to be applied. However, the standard AHP Eigen value prioritization approach cannot be used, when the decision-maker faces a complex and uncertain problem and expresses his/her comparison judgments as uncertain ratios, such as 'about two times more important', 'between two and four times less important', etc. A natural way to cope with such uncertain judgments is to express the comparison ratios as fuzzy sets or fuzzy numbers, which incorporate the vagueness of the human thinking. When comparing any two elements at the same level of the decision hierarchy, the uncertain comparison judgment can be represented by the fuzzy number . In this paper, triangular fuzzy numbers, which are a special class of the L-R fuzzy sets, is adopted. $=\left(l_{i j}, m_{i j}, u_{i j}\right)$ where $l_{i j}, m_{i j}$ and $\mathrm{u}_{\mathrm{ij}}$ are described by the measures between 1 and 9, corresponding to the mean, the lower and the upper bounds of triangular membership function respectively. The fuzzy membership functions are defined as very low- $(1,1,3)$; low- $(1,3,5)$; medium- $(3,5,7)$; high - $(5,7,9)$; very high- $(7,9,9)$;

$$
\tilde{\mathrm{A}}=\left[\begin{array}{cccc}
1 & \tilde{\mathrm{a}}_{12} & \cdots & \tilde{\mathrm{a}}_{1 \mathrm{n}} \\
\tilde{\mathrm{a}}_{21} & 1 & \cdots & \tilde{\mathrm{a}}_{2 \mathrm{n}} \\
\vdots & \vdots & \ddots & \vdots \\
\tilde{\mathrm{a}}_{\mathrm{n} 1} & \tilde{\mathrm{a}}_{\mathrm{n} 2} & \cdots & 1
\end{array}\right]
$$

where $\tilde{a}_{j i}=1 / \tilde{a}_{\mathrm{ij}}$. The normalized triangular fuzzy weight vector of the matrix $\tilde{\mathrm{A}}$ can be expressed as given below.

$\tilde{\mathrm{w}}=\left(\tilde{\mathrm{w}}_{1}, \tilde{\mathrm{w}}_{2} \ldots . \tilde{\mathrm{w}}_{\mathrm{n}}\right)^{\mathrm{T}}=\left(\left(\mathrm{w}_{1 \mathrm{~L}}, \mathrm{w}_{1 \mathrm{G}}, \mathrm{w}_{1 \mathrm{U}}\right),\left(\mathrm{w}_{2 \mathrm{~L}}, \mathrm{w}_{2 \mathrm{G}}, \mathrm{w}_{2 \mathrm{U}}\right), \ldots .\left(\mathrm{w}_{\mathrm{iL}}, \mathrm{w}_{\mathrm{iG}}, \mathrm{w}_{\mathrm{iU}}\right)\right)^{\mathrm{T}}$ where $\mathrm{w}_{\mathrm{iL}} \leq \mathrm{w}_{\mathrm{iG}} \leq \mathrm{w}_{\mathrm{iU}} \quad \forall \mathrm{i}$ The fuzzy logarithmic least square method (LLSM) developed by Wang et al (2006) is employed to obtain the vector of triangle fuzzy weights $\tilde{\mathrm{w}}=\left(\tilde{\mathrm{w}}_{1}, \tilde{\mathrm{w}}_{2} \ldots \tilde{\mathrm{w}}_{\mathrm{i}}\right)^{\mathrm{T}}$ through the optimization model of fuzzy LLSM. The optimization model is shown below.

$\min \mathrm{f}=\sum_{\mathrm{i}=1}^{\mathrm{n}} \sum_{\mathrm{j}=1, \mathrm{j} \neq \mathrm{i}}^{\mathrm{n}}\left(\left(\ln \mathrm{w}_{\mathrm{il}}-\ln \mathrm{w}_{\mathrm{ju}}-\ln \mathrm{a}_{\mathrm{ijl}}\right)^{2}+\left(\ln \mathrm{w}_{\mathrm{ig}}-\ln \mathrm{w}_{\mathrm{jg}}-\ln \mathrm{a}_{\mathrm{ijg}}\right)^{2}+\left(\ln \mathrm{w}_{\mathrm{iu}}-\ln \mathrm{w}_{\mathrm{jl}}-\ln \mathrm{a}_{\mathrm{iju}}\right)^{2}\right)$ subject to

$$
\mathrm{w}_{\mathrm{il}}+\sum_{\mathrm{j}=1, \mathrm{j} \neq \mathrm{i}}^{\mathrm{n}} \mathrm{w}_{\mathrm{ju}} \geq 1
$$




$$
\begin{aligned}
& \mathrm{w}_{\mathrm{iu}}+\sum_{\mathrm{j}=1, \mathrm{j \neq i}}^{\mathrm{n}} \mathrm{w}_{\mathrm{jl}} \leq 1, \\
& \sum_{\mathrm{i}=1}^{\mathrm{n}} \mathrm{w}_{\mathrm{jg}}=1, \\
& \sum_{\mathrm{i}=1}^{\mathrm{n}}\left(\mathrm{w}_{\mathrm{jl}}+\mathrm{w}_{\mathrm{iu}}\right)=2, \\
& 0<\mathrm{w}_{\mathrm{jl}} \leq \mathrm{w}_{\mathrm{jg}} \leq \mathrm{w}_{\mathrm{iu}}<1 .
\end{aligned}
$$

The triangular fuzzy number $\tilde{\mathrm{w}}_{\mathrm{i}}=\left(\mathrm{w}_{\mathrm{il}}, \mathrm{w}_{\mathrm{ig}}, \mathrm{w}_{\mathrm{iu}}\right)$ can be defuzzified by the following equation to obtain the crisp relative importance weight.

$$
\mathrm{w}_{\mathrm{i}}=\frac{\left(\mathrm{w}_{\mathrm{il}}+2 \mathrm{w}_{\mathrm{ig}}+\mathrm{w}_{\mathrm{iu}}\right)}{4} \mathrm{i}=1,2 \ldots . \mathrm{n} \text {. }
$$

\subsubsection{Main stages of FAHP}

The FAHP divides the decision problem into the following main steps (Mikhailov et al., 2003).

\section{Problem structuring}

The FAHP decision problem is structured hierarchically at different levels with each level consisting of a finite number of decision elements. The top level of the hierarchy represents the overall goal, while the lowest level is composed of all possible alternatives. One or more intermediate levels embody the decision criteria and sub-criteria.

\section{Assessment of Local priorities}

The relative importance (weights) of the decision elements (criteria and alternatives) is assessed indirectly from comparison judgments during the second step of the decision process. The decisionmaker is required to provide his/her preferences by comparing all criteria, sub-criteria and alternatives with respect to upper level decision elements. The values of the weights and scores are elicited from these comparisons .

\section{Calculation of global priorities}

Overall weight vector of the sub-criteria at the level prior to the final level is calculated by successively multiplying the priorities from previous level to subsequent levels.

\section{Results and analysis}

\subsection{Survey Questionnaire}

Survey questionnaire is developed from an extensive literature review, which examined a number of streams of research, including lean and agile supply chains, supply chain strategies, design requirements for various supply chains, confirmatory factory analysis. Twenty questions on the performance Indicators such as Operational Performance (OP); Customer Service Performance (CSP), Organizational Performance (ORP) and Flexibility (FL) are developed. The survey was sent to the medium and small organizations of Andhra Pradesh. The survey was addressed to personnel involving purchasing, production, marketing\& sales, logistic providers with mailing and personal contacts. A total of 225 out of 300 usable surveys were received. Another 20 surveys were returned 
and were not applicable because the respondent was no longer with the company. This resulted in an effective response rate of 75 percent.

\subsection{Descriptive statistics}

A summary of the demographic characteristics of the sample is presented in Table 1 . We have received 225 responses from three types of medium and small scale industries, namely (i) apparel manufacturing (ii) automotive spare parts and (iii) electronic components indicates that their interest in leagile supply chains. Responses indicate that people from important business are involved. Customer types namely Retailer, Bulk Manufacturer, Distributor and Customer direct are involved in the study. Approximately $75 \%$ had more than three years of working experience. This highlights the importance of working experience in the implementation of leagile supply chain management systems.

\section{Table 1}

Demographic Characteristics

\begin{tabular}{llll}
\hline Feature & Category & Frequency & Percentage \\
\hline Business function & Production & 65 & 29 \\
& Purchasing & 52 & 23 \\
& Sales \& Distribution & 108 & 48 \\
Type of Industry & Apparel & 18 & 42.85 \\
& Automotive & 10 & 23.81 \\
& electronics & 14 & 33.34 \\
Size of the Firm & $<50$ & 10 & 23.81 \\
& $50-100$ & 18 & 42.85 \\
& $100-200$ & 14 & 33.34 \\
Customer Type & Retailer & 09 & 21.43 \\
& Bulk Manufacturer & 10 & 23.81 \\
& Distributor & 15 & 35.71 \\
Experience of Employees & Customer direct & 08 & 19.05 \\
& $<2$ years & 56 & 24.89 \\
& $3-5$ Years & 75 & 33.33 \\
& $>5$ years & 94 & 41.78 \\
\hline
\end{tabular}

The study tested the measurement properties of the constructs (performance indicators) by confirmatory factor analysis. CFA was used to evaluate how well the measurement items for reflect latent variables in the hypothesized structure, due to the fact that this study is based on the theoretical basis from the previous research. Average Variance Extracted of each latent variable was more than 0.7 which showed that latent variables had reliability and convergence validity. The data of Average Variance Extracted (AVE) of Squared Multiple Correlation (SMC), Construct Reliability (CR) and latent variables are presented in Table 2. The standardized factor loadings $(>0.6)$ of the items indicate all the performance enablers are significantly related to their latent variables. In addition, Average Variance Extracted (AVE) of each the latent variable is greater than the cutoff point $(0.50)$ indicates the convergent validity. Composite Reliability (CR) and Average Variance Extracted (AVE) was more than 0.6 and 0.5 respectively indicating good construct reliability and adequate convergent validity. These findings suggested that the 16 items of four latent variables were reliable and had a high level of internal consistency. The latent variables (Operational performance, Customer service performance, Organizational performance and Flexibility) were evaluated based on the statistical significance of the indicator loadings with their reliability and variance extracted. Each variable's tvalues associated with each of the loadings exceed the critical values for the .05 significance level, thus showing that all variables are significantly related to their specified latent variables. Basing on the factor loadings, it can be concluded that there exists significant relationship between performance enablers and the respective performance indicators in respect of leagile supply chain.

The fit indices of the structure model of confirmatory factor analysis are shown in table 3 . The value of $\chi^{2 / \text { d.f }}$ is 5.3 indicates the close fit of the model (Carter and $\mathrm{Wu}, 2010$ ). As to the propriety of 
model, GFI value was 0.77 , AGFI was 0.68 , CFI was 0.98 indicates the highly close fit. Therefore, there were enough evidences to accept all the propositions (H1, H2, H3 and H4) were supported.

Table 2

Reliability and validity analytical results of measurement model

\begin{tabular}{|c|c|c|c|c|c|}
\hline $\begin{array}{l}\text { Latent Variable } \\
\text { (Performance } \\
\text { Indicators) }\end{array}$ & $\begin{array}{l}\text { Items } \\
\text { (Performance Enablers) }\end{array}$ & $\begin{array}{l}\text { Standardized Factor } \\
\text { Loadings }\end{array}$ & SMC & $\begin{array}{l}\text { Composite } \\
\text { Reliability (C R) }\end{array}$ & AVE \\
\hline Operational & Product cycle time & 0.97 & 0.95 & \multirow{4}{*}{0.98} & \multirow{4}{*}{0.85} \\
\hline \multirow[t]{3}{*}{ Performance (OP): } & Due date performance & 0.75 & 0.57 & & \\
\hline & Cost & 0.97 & 0.95 & & \\
\hline & Quality & 0.98 & 0.96 & & \\
\hline \multirow{4}{*}{$\begin{array}{l}\text { Customer Service } \\
\text { Performance(CSP): }\end{array}$} & Customer satisfaction & 0.93 & 0.86 & \multirow{4}{*}{0.92} & \multirow{4}{*}{0.73} \\
\hline & Delivery dependability & 0.85 & 0.73 & & \\
\hline & Responsiveness & 0.80 & 0.64 & & \\
\hline & Order fill capacity & 0.84 & 0.71 & & \\
\hline \multirow{4}{*}{$\begin{array}{l}\text { Organizational } \\
\text { Performance (ORP): }\end{array}$} & Market share & 0.97 & 0.93 & \multirow{4}{*}{0.96} & \multirow{4}{*}{0.87} \\
\hline & ROI & 0.93 & 0.87 & & \\
\hline & Sales growth & 0.99 & 0.98 & & \\
\hline & Green image & 0.83 & 0.68 & & \\
\hline \multirow[t]{4}{*}{ Flexibility (FL) } & Product development flexibility & 0.96 & 0.92 & \multirow{4}{*}{0.95} & \multirow{4}{*}{0.83} \\
\hline & Sourcing Flexibility & 0.97 & 0.94 & & \\
\hline & Manufacturing flexibility & 0.83 & 0.69 & & \\
\hline & IT flexibility & 0.88 & 0.77 & & \\
\hline
\end{tabular}

Table 3

Fit Indices of Structure Model

\begin{tabular}{lcc}
\hline Indicators & Propriety Indicators & Research Findings \\
\hline & $\chi^{2 / d . f}$ & 5.3 \\
Absolute Propriety Indicators & GFI & 0.77 \\
& AGFI & 0.68 \\
& SRMR & 0.05 \\
\hline & RMSEA & 0.14 \\
Relative Propriety Indicators & NNFI & 0.97 \\
& NFI & 0.97 \\
& CFI & 0.98 \\
\hline
\end{tabular}

It is an established fact that root mean square error of approximation (RMSEA) and standardized root mean square residual (SRMR) are also measures for model fitness. SRMR values less than 0.08 and RMSEA values less than 0.06 imply very good models (Brown, 2006; Hu and Bentler, 1999). The values of RMSEA (0.14) and SRMR (0.05) obtained in the study indicates the satisfactory fitness of the model. Therefore, generally speaking, the measurement model of this Leagile Supply chain suggesting a reasonably acceptable fit to the data.

\subsection{Prioritization of Performance Enablers}

The FAHP decision problem is structured hierarchically at different levels with each level consisting of a finite number of decision elements. The top level of the hierarchy represents the overall goal, while the lowest level is composed of all possible alternatives. One or more intermediate levels embody the decision criteria and sub-criteria. The hierarchy to analyze the performance of Leagile supply chain is shown below. The goal of the decision hierarchy is to analyze the performance of Leagile supply chain. Level 1 indicates the leagile supply chain performance indicators. Level 2 indicates the performance enablers. 


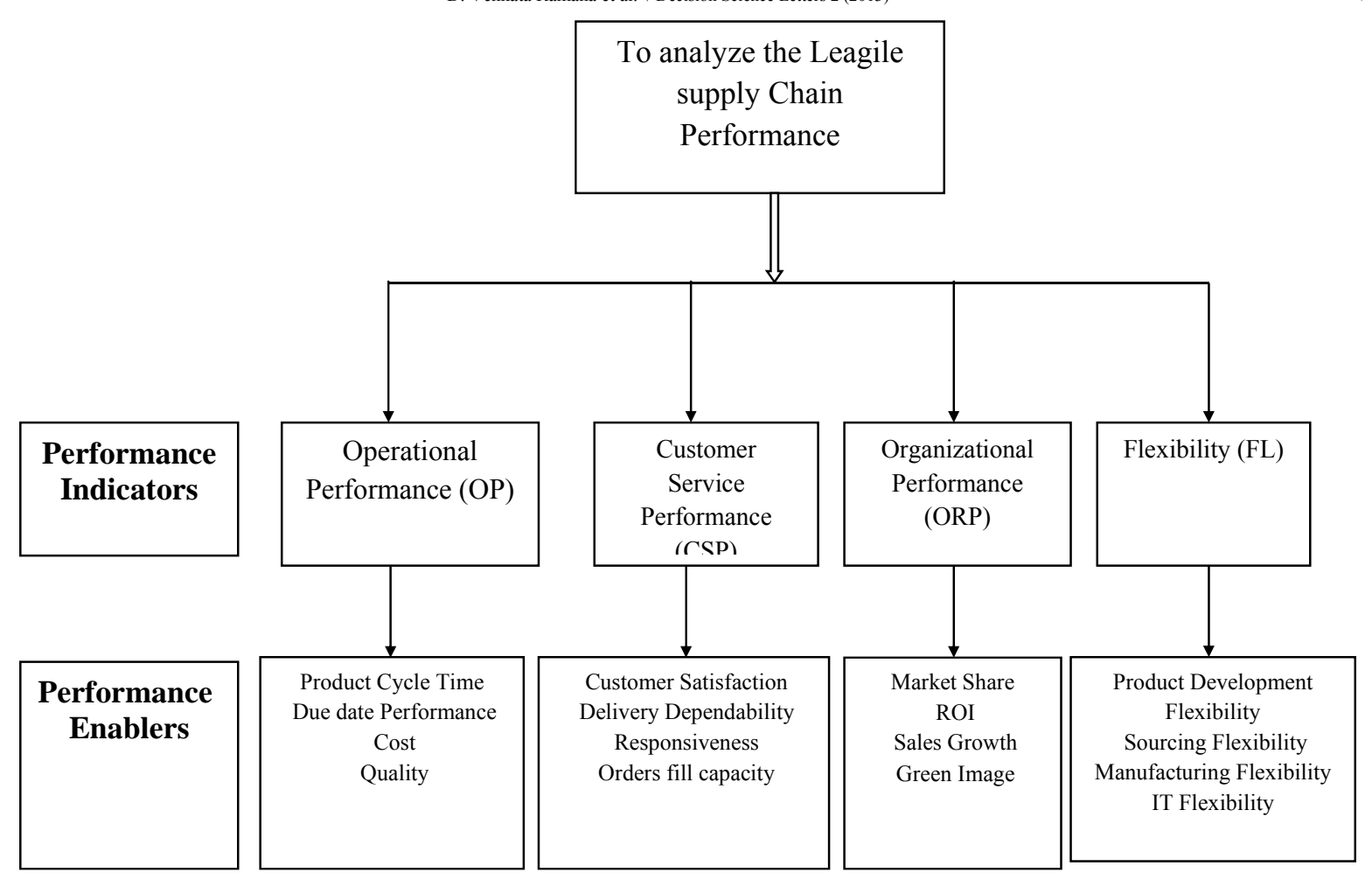

Fig. 2. Hierarchy of Performance Metrics of Leagile Supply Chain

\subsubsection{Local priorities}

The relative importance (weights) of the decision elements (criteria and alternatives) is assessed indirectly from fuzzy pair-wise comparison judgments. Fuzzy prioritization problem is developed using fuzzy pair-wise comparison matrices of performance indicators and performance enablers shown in the following Tables.

\section{Table 4}

Fuzzy pair-wise comparison of performance indicators

\begin{tabular}{lcccc}
\hline Performance Indicators & Customer service performance & Flexibility & $\begin{array}{c}\text { Operational } \\
\text { performance }\end{array}$ & $\begin{array}{c}\text { Organizational } \\
\text { performance }\end{array}$ \\
\hline Customer service performance & $(1,1,1)$ & $(1,3,5)$ & $(3,5,7)$ & $(5,7,9)$ \\
Flexibility & $(1 / 5,1 / 3,1)$ & $(1,1,1)$ & $(1,3,5)$ & $(3,5,7)$ \\
Operational performance & $(1 / 7,1 / 5,1 / 3)$ & $(1 / 5,1 / 3,1)$ & $(1,1,1)$ & $(1,3,5)$ \\
Organizational performance & $(1 / 9,1 / 7,1 / 5)$ & $(1 / 7,1 / 5,1 / 3)$ & $(1 / 5,1 / 3,1)$ & $(1,1,1)$ \\
\hline
\end{tabular}

Table 4.1

Fuzzy pair-wise comparison of Customer Service Performance Enablers

\begin{tabular}{lcccc}
\hline CUSTOMER SERVICE & Responsiveness & $\begin{array}{c}\text { Customer } \\
\text { satisfaction }\end{array}$ & Order fill capacity & $\begin{array}{c}\text { Delivery } \\
\text { dependability }\end{array}$ \\
PERFORMANCE & & $(1,1,3)$ & $(3,5,7)$ & $(7,9,9)$ \\
Responsiveness & $(1,1,1)$ & $(1,1,1)$ & $(1,1,3)$ & $(3,5,7)$ \\
Customer satisfaction & $(1 / 3,1,1)$ & $(1 / 3,1,1)$ & $(1,1,1)$ & $(1,1,3)$ \\
Orders fill capacity & $(1 / 7,1 / 5,1 / 3)$ & $(1 / 7,1 / 5,1 / 3)$ & $(1 / 3,1,1)$ & $(1,1,1)$ \\
Delivery dependability & $(1 / 9,1 / 9,1 / 7)$ & &
\end{tabular}

Table 4.2

Fuzzy pair-wise comparison of Flexibility Enablers

\begin{tabular}{lcccc}
\hline FLEXIBILITY & $\begin{array}{c}\text { Product development } \\
\text { flexibility }\end{array}$ & $\begin{array}{c}\text { Sourcing } \\
\text { flexibility }\end{array}$ & $\begin{array}{c}\text { Manufacturing } \\
\text { flexibility }\end{array}$ & IT flexibility \\
\hline Product development flexibility & $(1,1,1)$ & $(3,5,7)$ & $(5,7,9)$ & $(7,9,9)$ \\
Sourcing flexibility & $(1 / 7,1 / 5,1 / 3)$ & $(1,1,1)$ & $(3,5,7)$ & $(5,7,9)$ \\
Manufacturing flexibility & $(1 / 9,1 / 7,1 / 5)$ & $(1 / 7,1 / 5,1 / 3)$ & $(1,1,1)$ & $(3,5,7)$ \\
IT flexibility & $(1 / 9,1 / 9,1 / 7)$ & $(1 / 9,1 / 7,1 / 5)$ & $(1 / 7,1 / 5,1 / 3)$ & $(1,1,1)$ \\
\hline
\end{tabular}


Table 4.3

Fuzzy pair-wise comparison of Operational performance Enablers

\begin{tabular}{lcccc}
\hline OPERATIONAL PERFORMANCE & Quality & Due date performance & Cost & Product cycle time \\
\hline Quality & $(1,1,1)$ & $(1,1,3)$ & $(5,7,9)$ & $(7,9,9)$ \\
Due date performance & $(1 / 3,1,1)$ & $(1,1,1)$ & $(1,1,3)$ & $(5,7,9)$ \\
Cost & $(1 / 9,1 / 7,1 / 5)$ & $(1 / 3,1,1)$ & $(1,1,1)$ & $(5,7,9)$ \\
Product cycle time & $(1 / 9,1 / 9,1 / 7)$ & $(1 / 9,1 / 7,1 / 5)$ & $(1 / 9,1 / 7,1 / 9)$ & $(1,1,1)$ \\
\hline
\end{tabular}

Table 4.4

Fuzzy pair-wise comparison of Organizational performance Enablers

\begin{tabular}{lcccc}
\hline ORGANIZATIONAL PERFORMANCE & Market share & Return on investment & Green image & Sales growth \\
\hline Market share & $(1,1,1)$ & $(5,7,9)$ & $(5,7,9)$ & $(7,9,9)$ \\
Return on investment & $(1 / 9,1 / 7,1 / 5)$ & $(1,1,1)$ & $(1,1,3)$ & $(5,7,9)$ \\
Green image & $(1 / 9,1 / 7,1 / 5)$ & $(1 / 3,1,1)$ & $(1,1,1)$ & $(3,5,7)$ \\
Sales growth & $(1 / 9,1 / 9,1 / 7)$ & $(1 / 9,1 / 7,1 / 5)$ & $(1 / 7,1 / 5,1 / 3)$ & $(1,1,1)$ \\
\hline
\end{tabular}

Fuzzy pair wise comparison matrices shown in Tables $(4.1,4.2 \ldots .4 .5)$ are used to determine the priority of the performance indicators and enablers by solving non-linear programming as discussed in section 3.3 using LINGO solver. Overall weight of the enablers at the level prior to the final level is calculated by successively multiplying the priorities from previous level to subsequent levels.

\subsubsection{Calculation of global priorities}

The global priorities of Performance enablers of Leagile supply chain are shown in Table 5.

Table 5

Global Priorities

\begin{tabular}{|c|c|c|c|c|}
\hline PERFORMANCE INDICATORS & Priority & $\begin{array}{l}\text { Priority } \\
\text { Performance Enablers }\end{array}$ & Priority weights & $\begin{array}{l}\text { Global Priority of } \\
\text { Enablers }\end{array}$ \\
\hline \multirow{4}{*}{ Customer service performance } & \multirow{4}{*}{0.4442} & Responsiveness & 0.4131 & 0.1835 \\
\hline & & Customer satisfaction & 0.3239 & 0.1439 \\
\hline & & Order fill capacity & 0.1359 & 0.0604 \\
\hline & & Delivery dependability & 0.1271 & 0.0564 \\
\hline \multirow{4}{*}{ Flexibility } & \multirow{4}{*}{0.3188} & Product development flexibility & 0.4686 & 0.1494 \\
\hline & & Sourcing flexibility & 0.3286 & 0.1047 \\
\hline & & Manufacturing flexibility & 0.1014 & 0.0344 \\
\hline & & IT flexibility & 0.1014 & 0.0344 \\
\hline \multirow{4}{*}{ Operational performance } & \multirow{4}{*}{0.1283} & Product cycle time & 0.4138 & 0.0531 \\
\hline & & Quality & 0.3212 & 0.0412 \\
\hline & & Cost & 0.1580 & 0.0203 \\
\hline & & Due date performance & 0.1070 & 0.0137 \\
\hline \multirow{4}{*}{ Organizational performance } & \multirow{4}{*}{0.1087} & Market share & 0.4716 & 0.0513 \\
\hline & & Return on investment & 0.2659 & 0.0289 \\
\hline & & Green image & 0.1512 & 0.0164 \\
\hline & & Sales growth & 0.1113 & 0.0121 \\
\hline
\end{tabular}

In order to determine the importance of the performance indicators and enablers, the judgments collected from respondents to prepare the fuzzy pair wise comparison matrices. From these matrices fuzzy logarithmic least square method is adopted to determine the priority of Performance determinants and enablers. Local weights for performance indicator demonstrate that Customer Service Performance (0.4442) is the most important indicator to measure the performance of Leagile supply chain, followed by Flexibility $(0.3188)$, Operational performance $(0.1283)$ and organizational performance $(0.1087)$ reveals to be the dimensions with the moderate importance. The enablers of market share (0.4716), product development flexibility $(0.4686)$, product cycle time $(0.4138)$ and responsiveness $(0.4131)$ reveal the highest importance with regard to each dimension in sequence of Organizational performance, Flexibility, Operational performance and Customer Service Performance respectively. The enablers of Sourcing flexibility (0.3286), customer satisfaction (0.3239), Quality (0.3212) and return on investment $(0.2659)$ reveal the moderate importance with 
regard to each dimension in sequence of Flexibility, logistic performance, Operational performance and Organizational performance respectively.

Considering the global weights in Table 5, it is evident that the sixteen prioritized enablers for measuring the performance of Leagile supply chain. Basing on the global weight the enablers are categorized into three groups. Responsiveness (0.1835), Product development flexibility, (0.1494), Customer satisfaction (0.1439) and Sourcing flexibility (0.1047) are emerged as the most important enablers. Order filling capacity (0.0604), Delivery dependability (0.0564), Product cycle time (0.0531) and Market share (0.0513) are evolved as moderate important performance enablers. The remaining enablers namely, Quality (0.0412), Manufacturing flexibility (0.0344), IT flexibility (0, 0344), Cost (0.0203), Return on investment (0.0289), Green image (0.0164), Due date delivery performance (0.0137) and Sales growth (0.0121) are of less importance in measuring the performance of leagile supply chain.

\section{Conclusion}

This study suggested that the four-factor model with 16 items of the performance measurement of a leagile supply chain had a good fit. It is a valid and reliability measurement to identify the importance performance enablers under each performance indicator. Further, the relative weights of the enablers are determined in fuzzy environment. Responsiveness is emerged as the most important enabler. Product development flexibility, customer satisfaction and sourcing flexibility may be considered as equally important enablers. The enablers namely, order filling capacity, delivery dependability, product cycle time and market share are moderate important. The remaining enablers (Quality, cost, manufacturing flexibility, IT flexibility, return on investment, green image and sales growth) are relatively less important. The priority approaches for measuring the performance of leagile supply chain show the respondents' perceptions about the importance of them and assisted organizations recognize their strengths to move towards continuous improvement. Further, priority approach in fuzzy environment takes care of uncertainties in the subjective opinions of the stake holders. Although the previous literature has contributed to recognize various approaches in measuring the leagile supply chain performance little is known about the confirmatory and priority approaches, particularly in small and medium enterprises. The main strengths of this paper, hence, are two-folds: It recognizes the consistency approach and provides a method for prioritizing the performance enablers. This study proposed the use of FAHP to prioritize the performance enablers of leagile supply chain. In addition, the model also can help managers improve their understanding of performance measurement of leagile supply chains and enables decision makers to assess the performance of leagile supply chains. Furthermore, the application of analytical tool in determining weights for various performance enablers of leagile supply chain practice is suggested to utilize analytic network process (ANP) in terms interdependency property.

\section{References}

Agarwal, A., Shankar, R., \& Tiwari, M. K. (2006). Modeling the metrics of lean, agile and leagile supply chain: An ANP-based approach. European Journal of Operational Research, 173(1), 211225.

Agus, A., \& Hassan, Z. F. (2008). The strategic supplier partnership in a supply chain management with quality and business performance. International Journal of Business and Management Science, 1(2), 129.

Barua, A., Konana, P., Whinston, A. B., \& Yin, F. (2004). An empirical investigation of net-enabled business value. MIS Quarterly, 28(4), 585-620.

Bhatnagar, R., \& Sohal, A. S. (2005). Supply chain competitiveness: measuring the impact of location factors, uncertainty and manufacturing practices.Technovation, 25(5), 443-456.

Brown, T. A. (2006). Confirmatory Factor Analysis for Applied Research. Guilford Press, New York. 
Carter, S. A., \& Wu, K. D. (2010). Symptoms of specific and generalized social phobia: an examination of discriminant validity and structural relations with mood and anxiety symptoms. Behavior therapy, 41(2), 254-265.

Chen, C. Y., Leu, J. D., \& Chiou, C. H. (2006). The Impact of E-Supply Chain Capability on Competitive Advantage and Organizational Performance.International Journal of Electronic Business Management, 4, 419-427.

Gunasekaran, A., Patel, C., \& McGaughey, R. E. (2004). A framework for supply chain performance measurement. International journal of production economics, 87(3), 333-347.

Hau, L., \& Margurita, M. S. (1995). Product universality and design for supply chain management. Production Planning \& Control, 6(3), 270-277.

Hu, L. \& Bentler, P. M. (1999). Cutoff criteria for fit indices in covariance structure analysis: Conventional criteria versus new alternatives. Structural Equation Modeling: A Multidisciplinary Journal, 6(1), 1-55.

Hsu. C. W., \& Hu, A. H. (2008), Green supply chain management in the electronic industry, International Journal of Environmental science and Technology, 5(2), 205-216.

Li, S., Rao, S. S., Ragu-Nathan, T. S., \& Ragu-Nathan, B. (2005). Development and validation of a measurement instrument for studying supply chain management practices. Journal of Operations Management, 23(6), 618-641.

Li, S., Ragu-Nathan, B., Ragu-Nathan, T. S., \& Subba Rao, S. (2006). The impact of supply chain management practices on competitive advantage and organizational performance. Omega, 34(2), 107-124.

Lippman, S. (2001). Supply chain environmental management. Environmental Quality Management, 11(2), 11-14.

Mikhailov, L. (2003). Deriving priorities from fuzzy pair wise comparison judgments, Fuzzy Sets and systems, 134(3), 365-385.

Motade, M., Toloie-Eshlaghy, A., \& Halvachi-Zadeh, D. (2011). Assessment of supply chain agility in the automotive industry of Tehran. European Journal of Scientific Research, 61(2), 210-229.

Narasimhan, R., Swink, M., \& Kim, S. W. (2006). Disentangling leanness and agility: an empirical investigation. Journal of operations management, 24(5), 440-457.

Özkir, V., \& Demirel, T. (2011). A comprehensive analysis for the metrics of supply Chain design strategies, $15^{\text {th }}$ International Research/Expert Conference "Trends in the Development of Machinery and Associated Technology" TMT 2011, Prague, Czech Republic, 353-356.

Swafford, P. M., Ghosh, S., \& Murthy, N. (2006). The antecedents of supply chain agility of a firm: scale development and model testing. Journal of Operations Management, 24(2), 170-188.

Slack, N. (1987). The flexibility of manufacturing systems. International Journal of Operations \& Production Management, 7(4), 35-45.

Sower, V. E., \& Abshire, R. D. (2011). Radio frequency identification technology utilatation and Organizational Agiliy. Journal of Computer Information Systems, 24-33.

Samaranayake, P. (2005). A conceptual framework for supply chain management: a structural integration. Supply Chain Management: An International Journal, 10(1), 47-59.

Slack, N., Chambers, S., Johnston, R., \& Betts, A. (2008). Gerenciamento de operações e de processos. Bookman.

Van Hoek, R. I., Harrison, A., \& Christopher, M. (2001). Measuring agile capabilities in the supply chain. International Journal of Operations \& Production Management, 21(1/2), 126-148.

Vickery, S. K., Droge, C., \& Markland, R. E. (2007). Production competence and business strategy: do they affect business performance?. Decision Sciences, 24(2), 435-456.

Wang, Y. M. (2006). On lexicographic goal programming method for generating weights from inconsistent interval comparison matrices. Applied mathematics and computation, 173(2), 985991.

Zelbst, P. J., Green Jr, K. W., Abshire, R. D., \& Sower, V. E. (2010). Relationships among market orientation, JIT, TQM, and agility. Industrial Management \& Data Systems, 110(5), 637-658. 